in the study of development and differentiation. Bullough assembles the known facts, both those connected with the development of highor creatures and those connected with the evolutionary steps by which development as we know it today has established itself in the $3 \times 10^{9}$ years of lifo on Earth. He then applies to these facts the tools of rigorous analysis and strong inference which have been so successful in forwarding our understanding of molecular biology. He applies to embryology the picture of cell life as it has emerged from molecular biology. The result is an enormously stimulating and thoughtful book.

Bullough starts with the premise, with which I hope all biologists will agrce, that "it is (the) choice of programme whereby certain genes are activated while others are repressed which is the essence of differentiation". He therefore considers first the control of gene action in bacteria-bacteria are not only the presumed ancestors of tho eukaryots, but pre-date them by some $2.5 \times 10^{9}$ years. We know in some detail how gone action is controlled in bactoria. We know about operons, regulator genes, repressors and the control of repressor by small molecule effector substances. We know that bacteria possess operons concerned not only with metabolism but with such further basic processes as DNA replication and indeed with differentiation (sporulation). It is Bullough's conclusion that biologists must operate on the assumption that the operon mode of genetic control has constituted ono gift to the eukaryots from the prokaryots from which they are descended. This is also a proposition with which it is hard to disagree, particularly because the work of E. B. Lewis has established the existence of just such an operon in the gene complex bithornx for the control of a developmental pathway in Drosophila. Bullough, then, sces differentiation as regulated by a host of kinds of small molecules, each of which, by interaction with a specific reprossor protein, causes that repressor to repress or to not repress. Mitosis and cell multiplication in the liver, say, or in a tumour, are to be regarded as controlled by a particular kind of small molecule, a particular kind of "chalone", which interacts with a particular repressor and which, in turn, regulates the activity of the "mitosis operon".

But, as things turn out, there are still too few facts available to enable Bullough to make a detailed central dogma for differentiation. $\mathrm{H}_{\theta}$ cannot decide whether histones are the agents of repression in eukaryots, or are perhaps only for the control of long-term and stable repression, or possibly only for protection and packaging of the DNA. Although he would like to think that eukaryots possess repressor proteins which bind specifically to specific nucleotide sequences of the genome, he cannot point to such repressors, because no one has been able to discover them yet. The time has not yet arrived for the formulation of a detailed and specific model of the hardware and logic of the eukaryot genetic control system. That time is coming, though, and in the meantime Bullough's book makes excellent reading-ombryology and physiology viewed through the eyes of molecular biology.

J AMES BONNER volume of a treatise aimed at alleviating this situation as it arises in connexion with those zoological topics that are amenable to a chemical and biological approach.

The opening chapter on systematics by $J .0$. Corliss is likely to be of limited value to the chemist because of the terminology involved, a criticism that also applies to the second article on chemical aspects of ecology by $\mathrm{E}$. Fauré-Fremict. The very readable chapter on carbohydrates and respiration by J. F. Ryley, apart from being a good example of the fruitfulness of the combined chemical and zoological approach, demonstrates that the provision of introductory material is not incompatible with the subsequent advanced treatment of a topic. Nitrogen metabolism is dealt with comprehensively in an inspiring fashion by G. W. Kidder. The chapter by V. C. Dewey on lipids is rather too long for the newcomer but will be a most valuable source of reference. The important topic of axenic culture is ably discussed by D. M. Lilley in a very interesting chapter on growth factors. The lucid account of transport phenomena by R. L. Connor leads on to the discussion of digestion and hydrolases by $\mathbf{M}$. Müller.

The rest of the book is mainly about the problems associated with protozoan morphogenesis and its control. The topic is clearly introduced by E. D. Hanson in an articlo that is long but includes well chosen oxamples. Nucleic acids and their roplication, and the chemistry of cilia and flagella are the subjects of two short chapters by M. Mandel and F. M. Child respectivoly. Control of metabolism at the enzyme and substrate level and its importance in differentiation is the theme of a satisfying discussion on carbohydrate accumulation in protists by R. G. Pannbacker and B. E. Wright. Control at the gene level is considered by S. L. Allen. The examples of genic control of metabolic steps and of the elaboration of specific proteins are most enlightening as is the genetics of extranuclear nucleic acids. This chapter is exciting but not always explicit. The final chapter is a long one by B. M. Honigberg and deals mainly with the interesting biochemical constitution of the malarial parasite and the intriguing relationship between the morphology, biochemistry, evolution and parasitic habit of the trypano. somes.

The book covers a variety of topics and well demonstrates that the protozoa, because of their unique organization and biochemistry, are becoming increasingly important in biological research. Tho book succeeds in its aim of assembling a large amount of information in a stimulating form, but it fails in that it does not always cater for the range of readers onvisaged. This is particularly noticeable in the lack of suitable introductory information and the use of terminology, especially some ecological terms and chemical nomenclature, that is not readily explainable by reference to standard texts. A glossary would solve such a problem. Furthermore, the wealth of detail in some cases tends to obscure the main themes. Unfortunately, there has been a considerable amount of repetition of information, as can easily happen in a book of this type which relies on separate contributions.

C. R. SLADDEN

\title{
PROTOZOAN CHEMISTRY
}

\section{Chemical Zoology}

Vol. 1 : Protozoa. Edited by Marcel Florkin and Bradley T. Scheer. Pp. xvi+912. (Now York and London: Acadernic Press, 1967.) 354s.

ONE of the obstacles in undertaking investigations in new fields of inquiry is, as stated in the prefuce of this book, tho complex and scattered nature of the literature. Such a problem is encountered when an alliance is made between two disciplines such as chemistry and zoology. This book, which deals specifically with protozoa, is the first

\section{PARASITES OF LIVESTOCK}

\section{Veterinary Parasitology}

By Geoffrey Lapage. Appendices by T. E. Gibson and W. N. Beesloy. Second edition. Pp. xvi $+1182+34$ plates. (Edinburgh and London: Oliver and Boyd, 1968.) 168s. net.

When this book first appeared in 1956, it was recognized as an important contribution to voterinary science because there were no modern English textbooks dealing comprehensively with animal parasitology. As tho position 